Illinois State University

ISU ReD: Research and eData

Theses and Dissertations

3-30-2021

\title{
How The Covid-19 Closures And Restrictions Were Perceived By University Students As It Relates To Physical Activity Behaviors
}

Madison Brown

Illinois State University, madibrownie@gmail.com

Follow this and additional works at: https://ir.library.illinoisstate.edu/etd

Part of the Kinesiology Commons

\section{Recommended Citation}

Brown, Madison, "How The Covid-19 Closures And Restrictions Were Perceived By University Students As It Relates To Physical Activity Behaviors" (2021). Theses and Dissertations. 1356.

https://ir.library.illinoisstate.edu/etd/1356

This Thesis is brought to you for free and open access by ISU ReD: Research and eData. It has been accepted for inclusion in Theses and Dissertations by an authorized administrator of ISU ReD: Research and eData. For more information, please contact ISUReD@ilstu.edu. 
HOW THE COVID-19 CLOSURES AND RESTRICTIONS WERE PERCEIVED BY

UNIVERSITY STUDENTS AS IT RELATES TO PHYSICAL

ACTIVITY BEHAVIORS

MADISON BROWN

23 Pages

The purpose of this study was to examine how COVID-related closures and restrictions were perceived and received by students at a Midwestern university. Data were collected via an online survey that was distributed two weeks prior to the fall 2020 semester. Participants were 426 student volunteers. Eighty-one percent of respondents planned to return to campus in fall 2020. More than half had been physically active since the onset of COVID-19, primarily at home or outside. Most students reported willingness to attend the university student fitness center if masks were required at entry or during exercise $(60 \%)$, although fewer were willing to wear masks during exercise (32\%). Participation in virtual services offered by the university student fitness center during the pandemic, was low (1.4\%) compared to the previous in-person participation (32\%). Despite lockdown, many (70\%) students were able to maintain physical activity and find new ways to exercise (53\%) even when traditional fitness facilities were unavailable.

KEYWORDS: Covid-19, Physical Activity, Fitness Industry, Group Fitness, Exercise, Campus Recreation 


\section{HOW THE COVID-19 CLOSURES AND RESTRICTIONS WERE PERCEIVED BY UNIVERSITY STUDENTS AS IT RELATES TO PHYSICAL ACTIVITY BEHAVIORS}

MADISON BROWN

A Thesis Submitted in Partial Fulfillment of the Requirements for the Degree of

MASTER OF SCIENCE

School of Kinesiology and Recreation

ILLINOIS STATE UNIVERSITY 
C 2021 Madison Brown 
HOW THE COVID-19 CLOSURES AND RESTRICTIONS WERE PERCEIVED BY UNIVERSITY STUDENTS AS IT RELATES TO PHYSICAL ACTIVITY BEHAVIORS

MADISON BROWN

COMMITTEE MEMBERS:

Kristen Lagally, Chair

Rebecca Achen

Anna Miles 


\section{ACKNOWLEDGMENTS}

I would like to acknowledge and thank Dr. Lagally for supporting me through my thesis pursuits for the past two years, amidst a global pandemic. Your patience and guidance are greatly appreciated. I would also like to thank Dr. Achen and Dr. Miles for their patience, time, insight, and knowledge. I cannot express my gratitude enough. I not only value the mentorship you all have shown me through this process, but also the relationship we have developed professionally and personally.

M.B. 


\section{CONTENTS}

Page

ACKNOWLEDGMENTS

TABLES

CHAPTER I: INTRODUCTION 1

$\begin{array}{lr}\text { CHAPTER II: METHODS } & 6\end{array}$

$\begin{array}{lr}\text { CHAPTER III: RESULTS } & 8\end{array}$

$\begin{array}{ll}\text { CHAPTER IV: DISCUSSION } & 13\end{array}$

$\begin{array}{ll}\text { Practical Applications } & 17\end{array}$

$\begin{array}{ll}\text { CHAPTER V: LIMITATIONS } & 19\end{array}$

$\begin{array}{lr}\text { REFERENCES } & 20\end{array}$ 


\section{TABLES}

Table

Page

1. Participant Characteristics 


\section{CHAPTER I: INTRODUCTION}

Fitness professionals are continuously encouraging individuals to become more physically active, largely for the traditional benefits that physical activity has on health, but recently as a way to mitigate the effects of COVID 19. In a report from the CDC COVID-19 report team, of 7,162 patients with a positive COVID diagnosis, $37.6 \%$ had at least one underlying health condition or potential risk factor, such as diabetes mellitus $(10.9 \%)$, and cardiovascular disease $(9 \%)$ that might benefit from participation in physical activity (Chow et al., 2020). In the early months of COVID-19, ACSM released a call to action statement outlining considerations for sport and physical activity during the pandemic, noting that, "Overcoming obstacles to physical activity, using behavioral innovation specific to one's situations, is key to optimizing overall physical, mental and emotional wellbeing. The COVID pandemic should be viewed as an opportunity to expand our approach to prescribing physical activity" (Denay et al., 2020)

While continued physical activity was deemed important for optimizing health and wellbeing, many of the facilities where physical activity occurs indoors were asked to close temporarily due to the pandemic. In the state of Illinois, permitted activities included outdoor activity like walking, running, hiking, biking, which were permitted if social distancing was maintained. Individuals were also allowed to go to open parks and recreational areas. However, for a time, indoor physical activities were not permitted (Executive Order 2020-10 - Illinois. Gov, 2020.; CDC, 2020b). Fitness facilities were among the businesses of increased concern for the spread of COVID-19 because of factors like close contact, extended periods of time in an indoor space where ventilation might be an issue, and sharing or touch points for surfaces like seats and equipment handles, (CDC, 2020a). The coronavirus is thought to spread through respiratory 
droplets or small particles. These can then be inhaled into the nose, mouth, airways and lungs that could cause infection. While this is considered to be the main way the virus spreads, individuals can potentially contract COVID-19 by touching a surface or object that has the virus on it and then touch their mouth, nose, eyes (CDC, 2020c).

Although outdoor activity with social distancing was permitted, it may not have been an ideal way to be active for some, such as those not living in safe physical activity environments or whose weather is not compliant for outdoor activity. Additionally, some individuals prefer group exercise or activities requiring exercise equipment, such as weight training.

In an effort to keep people active during the time of COVID-19, the fitness industry has had to adapt. Early on in the pandemic, when facilities were closed, the fitness industry moved to increase and invest in virtual services as a response to lockdowns, quarantines and the associated health and fitness facility closures globally (Benveniste, 2020; Gange, 2020). Virtual services provide a viable and important option for maintaining physical activity when facilities were closed or required to limit capacity, create social distancing, cancel group sessions, and/or require mask wearing. They also provide an option for when the weather changes and makes outdoor exercise difficult or unsafe. Mindbody, cloud-based scheduling software reported that in 2019, 7\% of Mindbody App consumers used live streamed workouts, but during COVID-19, that increased over 80\% (McAlister, 2020). Campus Rec Magazine described the increase in online training as a "wake-up call for higher education to start meeting folks where they are" (Trotter, 2021).

Virtual fitness can be defined as a fusion of exercise and technology (Hogan, 2018) and/or fitness sessions where the instructor/trainer and participant are not physically in the same location. To mimic traditional in-person experiences like group fitness and personal training, the 
virtual realm can include virtual group fitness and virtual or remote coaching. These virtual offerings may be synchronous or asynchronous (American Council on Exercise, 2020). Asynchronous virtual sessions provide no real time interaction between the instructor or fellow participants. During the pandemic, $70 \%$ of exercisers used pre-recorded workout videos (asynchronous) (Weddle, 2020). Weddle (2020) also found that 75\% of Mindbody app users took advantage of live stream video workouts (synchronous). Synchronous virtual sessions provide the opportunity for interaction between the instructor and one or more participants, and can be one-way broadcasted so that only the instructor is seen and participants are not or twoway broadcasted where the instructor can be seen and if the participant chooses, they can also be seen by the instructor and any other participants in the session (ACE, 2020). The latter option creates more of a "group" fitness session dynamic. The data on increased participation in virtual offerings, whether asynchronous or synchronous, individual or group, is promising for fitness professionals who want to promote physical activity and provide physical activity options for their clients, whether or not COVID-19 is a concern.

In late summer of 2020, fitness facilities reopened for one-on-one personal training and outdoor group exercise. The heightened risk of COVID-19 spreading when exercising, social distancing, restrictions on group exercise class sizes, strict cleaning procedures, and mask wearing (at least during non-exercise activities ${ }^{1}$ ) have become important considerations for fitness facilities in order to remain open, safe, and solvent (Restore Illinois- Phase 4, 2020). A number of facilities have been forced to close permanently (Biron, 2020.), and others may not survive if continued closures occur due to future potential spikes in COVID-19. In Illinois, facilities that have opened were required to add additional protocols to limit risk of exposure and

\footnotetext{
${ }^{1}$ Early re-opening did not require masks during ex ercise, but in November 2020, Illinois moved back to tier 3 which required masks to be worn even while a ctively ex ercising. This however is not true for a ll states.
} 
spread, including employee and patron health checks and addition of physical barriers between employees and patrons. Many facilities had to modify equipment layouts to maintain social distancing of at least 6 feet apart between equipment. Some other changes were promoting electronic or contactless payment, adding foot-traffic directions, increase sanitation stations, limit the facility occupancy, and require attendance registrations (CDC, 2020a).

A major change for the individual patron was the requirement of face coverings, which was a condition for re-opening facilities. Requirements varied from facility to facility, with some encouraging masks, and others requiring it. Some required masks only during non-active time and others required it at all times, including during activity. While it is understandable that both facilities and individuals might have concerns about the requirement of masks, there was little research in this area at the time. Motoyama et al., (2016), investigated the effects of airflowrestricting masks on performance during a resistance training session and found that completed repetitions were lower with the mask then without, suggesting that a mask could have a negative effect on muscular performance. These researchers also found that ratings of perceived exertion and maximal heart rate in the mask wearers were higher than the control. Li et al. (2005) looked at the effects of wearing N95 and surgical facemasks on heart rate, thermal stress and subjective sensation. Heart rate and subjective ratings of discomfort were found to be significantly higher when wearing the N95 facemasks compared to the surgical masks. In contrast, Shaw et al., (2020) examined no mask, surgical mask, and cloth mask conditions during a progressive cycle ergometer exercise test and found there was no difference between the face mask and no mask conditions for time to exhaustion, ratings of perceived exertion, and peak power. In a commentary published in the British Journal of Sports Medicine, authors indicated that mask wearing during exercise may lead to potential breathing restriction and discomfort" and requires 
"balancing benefits versus possible adverse events"(BMJ, 2020). Data on individual perceptions of mask wearing during exercise were minimal, and it was unclear how consumers might respond to mask requirements at fitness facilities. As indicated above, the pandemic has significantly impacted fitness facilities, including those on college campuses. A survey conducted by National Intramural-Recreational Sports Association on 447 institutions of higher learning during the early phase of the pandemic (April 1-3,2020) found that $57 \%$ of recreational facilities closed with no scheduled re-opening, and $40 \%$ of facilities were closed for the remainder of the academic year. (NIRSA, April 2020). Nevertheless, some university student fitness centers were able to continue to provide services virtually and reopened limited in-person activities (with restrictions) for the fall semester of 2020. The purpose of this study was to examine one such facility at a Midwestern university to understand how COVID-19 related closures and restrictions upon reopening were perceived by students. 


\section{CHAPTER II: METHODS}

Potential participants for the study were any student of the university who had agreed to receive electronic notifications of survey research. Following approval by the University's Institutional Review Board, the survey was distributed via email in early August 2020. Participants were sent an email to their university email address with the survey link provided. The survey was intentionally distributed prior to the start of the semester. The survey was open for a total of 7 days with one reminder email.

Once participants clicked the link to the survey, they were directed to the informed consent letter at the beginning of the web-based survey. By clicking the consent button, participants indicated their willingness to participate and that they were 18 years of age or older. Completion of the survey implied participant consent. No verbal presentation occurred, and participant signatures were not required. Coercion was minimized by using participants on a volunteer basis. The consent document indicated that the choice to participate or to refrain would in no way affect the participant's standing at the university.

The survey was developed using Qualtrics software. The survey contained 33 questions including age, sex, and other demographics. However not all questions were asked to every participant based on the responses provided (due to utilization of 'Skip Logic'). Questions were developed by the researchers to target specific perceptions and reactions to the pandemic in terms of physical activity behaviors. To assess face validity, the survey was completed by nonparticipants prior to distribution. The survey took less than 10 minutes to complete. Specific questions are provided in the Results section.

Data were entered into and analyzed using SPSS software. This study took a nonexperimental cross-sectional approach using primarily quantitative data from the survey, 
although there were opportunities to indicate "other" options and to elaborate on particular answers. Similar statements written in as clarification for "other" selections were evaluated by the researchers and coded based on similar responses to those questions. This occurred only with the write-in responses to "What new ways did you find to exercise during the pandemic"? We found there to be three themes to the written responses, focusing on the type of exercise, the location of exercise, and whether or not there was supervision during the exercise. We then created three new variables: Exercise Type 1, Location of exercise and Supervision (yes/no). Once the qualitative data were modified in this way, frequencies and descriptives were run in SPSS to examine the characteristics of respondents and how they perceived physical activity opportunities and the COVID-related limitations surrounding those. 


\section{CHAPTER III: RESULTS}

In total, 426 Illinois State University students completed the survey. Participant mean age was $21.7 \pm 5.6$ years, mean height was $168.9 \pm 9.8 \mathrm{~cm}$, mean weight was $158.7 \pm 40.3 \mathrm{lbs}$, and mean BMI was $25.1 \pm 5.7 \mathrm{~kg} / \mathrm{m}^{2}$. Additional characteristics including year in school, BMI classification, and gender identification can be found in Table 1. It is important to note that $15.7 \%(n=67)$ of our respondents were either freshman or transfer students, and so were not included in the analyses for questions that required previous attendance at the university (e.g. "Have you exercised at the Student Fitness Center" or "On a weekly basis, how frequently did you attend the Student Fitness Center?"). With freshman and transfers removed, the remaining sample size for analyses was 359 . Of those $359,73 \%(n=262)$ had previously exercised at the SFC and had done so seven days per week (2\%), 4-6 days per week (16 \%), 2-4 days per week $(34 \%)$, or 0 -1 days per week $(21.2 \%)$. The remaining participants $(27 \%)$ did not respond to this question.

All 426 participants were asked "Have you been physically active since the student fitness center closed in March 2020" (so between March and August 2020). Seventy percent $(n=297)$ of respondents reported being physically active, while $25 \%(n=108)$ said they had not been physically active, and 5\% did not answer this question. Those who reported being active during COVID-19 were asked "If you have been active, how". Of those, $57 \%$ turned to home workouts, 49\% engaged in outdoor activities, $12 \%$ used fitness apps and $4 \%$ participated in virtual group fitness either hosted by the student fitness center or other providers. In addition to asking whether or not they had remained active and how, the survey asked participants to respond "yes" or "no" to "Have you found any new ways to exercise during COVID-19 closures". Fifty-three percent $(n=227)$ of participants responded positively that they had found 
new ways to exercise during the pandemic and $43 \%(n=182)$ also provided open- ended responses about the new ways of exercise they engaged in. Responses to this question might or might not have included the same activities listed when respondents were asked if they were physically active during COVID-19 closures. The researchers found three general themes to the open-ended responses regarding new ways to exercise: type of exercises, location and presence of supervision (i.e. instructor vs. self-led), and created three new variables based on the openended responses: Exercise Type 1, Location of exercise and Supervision (yes/no). Because not all 182 respondents indicated types of exercise, location or information on supervision, we have provided the absolute number of participants who did provide this information rather than percentages. Open-ended responses for location of the new exercise included at home $(n=68)$, outside $(n=69)$ or at a gym $(n=5)$. The types of new exercises included walking $(n=31)$, jogging or running $(\mathrm{n}=32)$, cycling $(\mathrm{n}=27)$, yoga $(\mathrm{n}=11)$, weightlifting $(\mathrm{n}=12)$, Rollerblading $(\mathrm{n}=3)$, Sports ( $\mathrm{n}=6)$, water activities $(\mathrm{n}=3)$, and bodyweight activities $(\mathrm{n}=12)$. Some $(\mathrm{n}=47)$ specifically stated they followed an instructor, app or specific video, while others $(\mathrm{n}=5)$ specifically stated they performed self-led activities.

Participants were asked "Do you intend to return to campus in the Fall?". The majority $(81 \%, \mathrm{n}=426)$ of respondents planned to come to campus at the onset of the fall semester 2020 . Use of the student fitness center in fall 2020 required masks to be worn upon entry, but not during exercise. All 426 participants were asked "Will you still exercise at the Student Fitness Center if masks are required for entry?" and "Will you still exercise at the Student Fitness Center if masks are required during exercise?". Sixty percent (n=256) said they would attend the SFC if masks were required upon entry and $32 \%(n=136)$ said they would attend if masks were required during exercise, while $20 \%(n=85)$ said no on attending if masks were required at entry 
and $39 \%(n=166)$ said no if required during exercise. Fifteen percent $(n=64)$ were unsure if they would return to the SFC if masks were required at entry and $24 \%(n=102)$ were unsure about attending if masks were required during exercise. Five percent did not respond to these questions. When looking at only freshman and transfer student responses to this same question, $85 \%(\mathrm{n}=57)$ said they would attend if masks were required upon entry and $51 \%(\mathrm{n}=34)$ saying yes if required during exercise. Only with only $9 \%(n=6)$ said no if required upon entry and $24 \%$ $(\mathrm{n}=16)$ said no if required during exercise. When only upper level students were examined, $56 \%$ $(n=200)$ said they would attend the SFC if masks were required at entry, and 28\% $(n=101)$ would if masks were required during exercise. Twenty two percent $(n=79)$ said they would not attend if masks were required for entry, and 42\% ( $\mathrm{n}=151)$ wouldn't attend if masks were required during exercise.

Because of facility closures, participation in virtual offerings was of interest and examined in this survey. Virtual offerings at this university were primarily group fitness. As such, questions focused on participation in virtual group fitness, rather than other potential virtual offerings, such as personal training. All 426 participants were asked "Do you consider virtual group fitness the same as in-person group fitness?", and seventy-six percent $(\mathrm{n}=323)$ did not consider virtual group fitness the same as in-person fitness, while $17 \%(n=74)$ did. The remaining questions regarding virtual group fitness were directed at only individuals who reported being physically active $(\mathrm{n}=297)$. In response to "Have you participated in any virtual Group Fitness offerings since the SFC closed in March", 4\% $(n=18)$ said they had participated. When asked to elaborate on the source of the virtual group fitness in which they had participated ("Was the virtual group fitness hosted by the SFC?"), 6 (1.4\%) responded that they had used the 
virtual offerings provided by this university, and 12 (2.8\%) used virtual group offerings provided by another entity. 
Table 1. Participant Characteristics

\begin{tabular}{lll}
\hline & \% of respondents & n \\
\hline Gender Identification & & 217 \\
\hline Female & 50.9 & 77 \\
Male & 18.1 & 5 \\
Non-binary & 1.2 & 1 \\
Gender fluid & .2 & 1 \\
Gender Queer & .2 & 125 \\
No response & 29.3 & \\
\hline BMI & 4.0 & 17 \\
\hline Underweight & 47.7 & 203 \\
Normal & 21.1 & 90 \\
Overweight & 8.0 & 34 \\
Obesity 1 & 3.5 & 15 \\
Obesity 2 & 2.1 & 9 \\
Extreme Obesity & 13.6 & 58 \\
No response for height and/or weight & & 58 \\
\hline Year in School & 13.6 & 76 \\
\hline Freshman & 17.8 & 99 \\
Sophomore & 23.2 & 131 \\
Junior & 30.8 & 62 \\
Senior & 14.6 & \\
Graduate & *Transfer students are included with their respected grade \\
\hline
\end{tabular}

*Transfer students are included with their respected grade 


\section{CHAPTER IV: DISCUSSION}

The COVID-19 pandemic hit the United States in early March 2020, resulting in an abrupt change of "normalcy". Isolation, business and university closures, physical distancing and personal protective equipment requirements left many to find a new "normal" in many ways, including physical activity. Most physical activity centers were directly affected by the COVID19 closures, meaning that individuals had limited access to structured physical activity programming or equipment if they relied on gyms for that access. Many college campuses were completely closed, including student fitness centers.

The aim of the study was to better understand university students' physical activity behaviors and perspective towards physical activity prior to and during the pandemic, as well as examine their plans to return to activity upon facility reopening or returning to campus. To do so, we administered a survey asking about student physical activity behavior during COVID-19 closures and plans to return to campus and physical activity, approximately two weeks prior to the fall 2020 semester.

The majority of respondents (74\%), not including freshman and transfer students, had previously used the SFC multiple times per week, so facility closure in March 2020 likely affected physical activity plans for these individuals. Nevertheless, $70 \%$ reported being physically active after closure of facilities (this value includes freshman and transfer students). When asked how they continued to be active, the majority of respondents indicated that they selected home or outdoor exercise, but fitness apps and virtual fitness were also used. Outdoor exercise was a popular response regardless of whether the respondent was indicating how they continued to be active or what new ways they had found to be active. It is important to note that this study took place in mid-August, during the warmer months for the Midwest, which could 
have affected participation in outdoor exercise in multiple ways - either promoting it because it was pleasant outside, or minimizing due to excess heat. We cannot determine from our data if people would have been more or less likely to participate in outdoor exercise if closures had occurred at a different time of the year. It would be interesting for additional research to examine how physical activity choices may have changed when the weather turned colder, although in the region where these data were collected, fitness facilities were permitted to remain open during winter months provided exercisers wore masks.

Early in the pandemic, the use of masks during physical activity elicited varying viewpoints, although there was limited research in the area (Li et al., 2005; Motoyama et al., 2016; CDC., 2020d). Additional research has been published subsequently, indicating that exercise performance does not seem to decrease as a result of mask wearing (Shaw et al., 2020). Initial recommendations from the $\mathrm{CDC}$ indicated concern over masks during high intensity exercise and possible reduced effectiveness of masks if they were to get damp from breath or sweat (CDC, 2020d). Nevertheless, masks were required in urban areas and strongly suggested in others, even during exercise, both indoors and out (CDC., 2020d; Executive Order 2020-32 Illinois. Gov, 2020). At the time the survey was administered, masks were required for entry into the university facility, but not during exercise. Eighty-one percent of students indicated a plan to return to campus in fall 2020. More than half of all 426 respondents said they would return to the student fitness center on campus if masks were required upon entry, less than half said they would if it was required during exercise. Our survey did not determine a rationale for the response to mask wearing. Compared to upperclassmen, freshman and transfer students appeared to be more willing to exercise at the student fitness center if masks were required at entry ( $85 \%$ vs $56 \%)$ and/or during exercise ( $51 \%$ vs. $28 \%)$. Perhaps new students' eagerness to 
engage on campus activities outweighed concerns over mask wearing to a greater extent than with upperclassmen.

Many respondents (53\%) indicated finding new ways to exercise during pandemic closures. Specifically, the types of new exercises cited included walking $(\mathrm{n}=31)$, jogging or running $(n=32)$, cycling $(n=27)$, yoga $(n=11)$, weightlifting $(n=12)$, rollerblading $(n=3)$, sports $(\mathrm{n}=6)$, water activities $(\mathrm{n}=3)$, and bodyweight activities $(\mathrm{n}=12)$. Broadening horizons in the ways that one is physically active is beneficial from a motivation and adherence standpoint. JuvancicHeltzel et al., (2013) found a higher variety of exercise equipment led to increased enjoyment of and participation in physical activity, so in this way at least, perhaps the pandemic facility closures had an upside. The types of activities chosen likely reflect the available options. Activities that require minimal equipment were the most frequently cited new ways to exercise. Not surprisingly however, Fitt Insider indicates that there has been a $500 \%$ increase in interest in home exercise equipment and a $467 \%$ increase in Peloton downloads as a result of the pandemicrelated facility closures (8 Charts That Explain COVID-19's Impact on the Fitness Industry, 2020). Future research might examine whether individuals maintained these new forms of exercise over the course of the pandemic and/or if home exercise equipment was purchased and influenced exercise choices.

Virtual fitness, particularly group fitness, was also addressed in the survey. It is interesting that prior to the pandemic $32 \%(\mathrm{n}=138)$ of the respondents participated in group fitness, however during the pandemic only $4 \%(\mathrm{n}=18)$ participated in virtual group fitness. This is not consistent with reports from Mindbody who found an increase from $7 \%$ to over $80 \%$ of app users participating in virtual offerings over the course of the COVID-19 pandemic (McAlister, 2020). The reasons for the lower rates of participation in our subjects are unclear, 
although it was possible that students were simply not aware of the offerings given the level of marketing devoted to this area. The lack of participation could also be attributed to the perception by the participants in the present study that virtual group fitness is not the same as inperson. Although we do not know the reason why, $76 \%(\mathrm{n}=323)$ indicated that they did not consider virtual the same as in-person group fitness. Further research on the perception of and participation in virtual group fitness would be useful for fitness professionals, as it is anticipated that virtual fitness will continue to be important. MindBody indicates that $43 \%$ of consumers plan to continue their previous routines but also add pre-recorded or live stream fitness programming post-COVID-19 (McAlister, 2020).

The aim of the study was to better understand university students' physical activity behaviors and perspective towards physical activity prior to and during the pandemic, as well as examine their plans to return to activity upon facility reopening or returning to campus. In summary, many students were able to maintain physical activity and find new ways to exercise during facility closures. Participation in virtual group fitness offerings at the university examined in the present study was low, which is in contrast with data on national participation in virtual fitness offerings. Students also reported varying degrees of willingness to return to physical activity at the university SFC given mask requirements. The majority were willing to return if masks were required for entry, with significantly less willing to return if masks were required during exercise. While it is hoped that facilities will reopen or remain open given decreasing rates of infection and vaccinations, mask wearing may continue to be required, so further research examining participant perceptions and experiences of mask wearing is warranted. Additionally, virtual fitness may remain an important offering, and so future research 
on participation in, perceptions of, and preferences for various virtual fitness modes is also warranted.

\section{Practical Applications}

As fitness professionals look to learn from this time and ways to improve their offerings, this paper can lend some insight to the perceptions of those they look to service. It is reassuring that $70 \%$ of respondents were still physically active during the pandemic. This shows us that people might not need the traditional fitness center or equipment to be active. It might also show us how resilient people are in finding a way to be active, with $53 \%$ of our respondents finding new ways to exercise.

Upon re-opening and operating under this "new normal", facility managers need to be aware of the perception their members have regarding mask requirements during exercise. This paper shows that respondents were more apt to return to the fitness center if masks were just required at entry rather than during exercise. With respect to memberships, profit and promotion of physical activity, this might be something a facility needs to consider, while maintaining safety for clients. University fitness centers largely look to limit barriers for their students in terms of recreational activity, and mask requirements might present a new barrier. Where feasible, fitness centers might look to increase outdoor offerings and prioritize social distancing and cleaning protocols to maintain safety when masks are not worn during exercise.

Prior to COVID-19 university fitness centers largely focused on in-person services and rarely provided virtual options. This shifted during the pandemic, in part because facilities closed but also as a way to still service those in lockdown and quarantine. While this paper doesn't fully investigate the reasons behind the responses, it does shed some light on college student's virtual fitness interest. During the pandemic, this facility saw only $4 \%$ participation in virtual group 
fitness and more specifically only $1.4 \%$ of which used the university's services. Campus Rec professionals need to consider their population and the type of services they prefer in order to continue to engage their clients and promote physical activity. In-person and virtual group fitness may not be considered to be the same, but that could be both positive or negative, depending on the individual. Some individuals may be more likely to participate in group fitness if virtual, whereas other may miss the in-person dynamic. As such, it would be beneficial to further examine the aspects of interest in group fitness - in-person or virtual. 


\section{CHAPTER V: LIMITATIONS}

This study was not without limitations. The survey was only distributed at one midsized Midwest university; therefore, it is not representative of all university students or other universities. This survey was administered during a warm summer month (August), a particular time of year which may have resulted in responses different than at another time. Survey flow and skip logic had issues that caused participants to not receive some questions that may have elicited additional information. The survey asked broad questions about physical activity behaviors and failed to ask why such response was given, this could be valuable insight to the motives behind a behavior. While the survey asked about virtual group fitness services from the SFC, this service was new, poorly marketed, and largely took place over the summer, a time when students are often removed from university services. This could be the reason for low virtual participation results. A follow up survey could be interesting to see if these habits and perspectives stayed consistent or changed throughout the semester and year. 


\section{REFERENCES}

American Council on Exercise. (2020). Delivery Options for Group Fitness. Retrieved September 23, 2020, from https://www.acefitness.org/education-and-resources/professional/expertarticles/7653/delivery-options-for-group-fitness/

Benveniste, A. (2020, April 1). The \$94 billion fitness industry is reinventing itself as Covid-19 spreads. CNN. Retrieved April 1, 2020, from https://www.cnn.com/2020/04/01/business/fitness-studios-coronavirus/index.html

Biron, B. (2020). Cyc Fitness and YogaWorks just filed for bankruptcy - here are the 7 fitness and sporting goods companies that have folded in 2020 as the pandemic upends how Americans exercise. Business Insider. Retrieved November 29, 2020, from https://www.businessinsider.com/fitness-sporting-goods-retailers-filed-bankruptcyliquidation-closing-stores-2020-9

BMJ. (2020, June 12). Should people wear a face mask during exercise: What should clinicians advise? BJSM Blog - Social Media's Leading SEM Voice. Retrieved March 22, 2021, from https://blogs.bmj.com/bjsm/2020/06/12/should-people-wear-a-face-mask-during-exercisewhat-should-clinicians-advise/

CDC. (2020a, February 11). Community, Work, and School. Centers for Disease Control and Prevention. Retrieved February 16, 2021, from https://www.cdc.gov/coronavirus/2019ncov/community/organizations/gym-employers.html

CDC. (2020a, February 11). COVID-19 and Your Health. Centers for Disease Control and Prevention. https://www.cdc.gov/coronavirus/2019-ncov/daily-life-coping/participate-inactivities.html 
CDC. (2020c, October 28). COVID-19 and Your Health. Centers for Disease Control and Prevention. Retrieved March 30, 2021, from https://www.cdc.gov/coronavirus/2019ncov/prevent-getting-sick/how-covid-spreads.html

CDC. (2020d, February 11). COVID-19 and Your Health. Centers for Disease Control and Prevention. Retrieved March 22, 2021, from https://www.cdc.gov/coronavirus/2019ncov/prevent-getting-sick/cloth-face-cover-guidance.html

Chow, N., Fleming-Dutra, K., Gierke, R., Hall, A., Hughes, M., Pilishvili, T., Ritchey, M., Roguski, K., Skoff, T., \& Ussery, E. (2020). Preliminary Estimates of the Prevalence of Selected Underlying Health Conditions Among Patients with Coronavirus Disease 2019 United States, February 12-March 28, 2020. Morbidity and Mortality Weekly Report, 69(13), 382-386. https://doi.org/10.15585/mmwr.mm6913e2

Denay, K. L., Breslow, R. G., Turner, M. N., Nieman, D. C., Roberts, W. O., \& Best, T. M. (2020). ACSM Call to Action Statement: COVID-19 Considerations for Sports and Physical Activity. Current Sports Medicine Reports, 19(8), 326-328. https://doi.org/10.1249/JSR.0000000000000739

Executive Order 2020-10 - Illinois.gov. (2020, March 20). Retrieved February 16, 2021, from https://www2.illinois.gov:443/pages/executive-orders/executiveorder2020-10.aspx Executive Order 2020-32 - Illinois.gov. (2020, April 30). Retrieved March 24, 2021, from https://www2.illinois.gov:443/Pages/Executive-Orders/ExecutiveOrder2020-32.aspx Gagne, Y. (2020, October 14). The fitness industry will survive the pandemic, but it will look very different. Fast Company. Retrieved November 23, 2020, from https://www.fastcompany.com/90553869/the-fitness-industry-will-survive-the-pandemicbut-it-will-look-very-different 
Juvancic-Heltzel, J. A., Glickman, E. L., \& Barkley, J. E. (2013). The Effect of Variety on Physical Activity: A Cross-Sectional Study. Journal of Strength and Conditioning Research, 27(1), 244-251.https://doi.org/10.1519/JSC.0b013e3182518010

Li, Y., Tokura, H., Guo, Y. P., Wong, A. S. W., Wong, T., Chung, J., \& Newton, E. (2005). Effects of wearing N95 and surgical facemasks on heart rate, thermal stress and subjective sensations. International Archives of Occupational and Environmental Health, 78(6), 501509. https://doi.org/10.1007/s00420-004-0584-4

McAlister, L. (2020, May 29). Here's How COVID-19 Has Changed Fitness. Mindbody. Retrieved September 20, 2020, from https://www.mindbodyonline.com/business/education/blog/heres-how-covid-19-haschanged-fitness

Motoyama, Y., Joel, G., Pereira, P., Esteves, G., \& Azevedo, P. (2016). Airflow-Restricting Mask Reduces Acute Performance in Resistance Exercise. Sports, 4(4), 46. https://doi.org/10.3390/sports4040046

NIRSA. (2020). Campus Recreation Response to Covid-19. National Intramural-Recreational Sports Association. Retrieved October 26,2021, from https://nirsa.net/nirsa/wpcontent/uploads/nirsa-covid19-impact-survey-infographic.pdf

Shaw, K., Butcher, S., Ko, J., Zello, G. A., \& Chilibeck, P. D. (2020). Wearing of Cloth or Disposable Surgical Face Masks has no Effect on Vigorous Exercise Performance in Healthy Individuals. International Journal of Environmental Research and Public Health, 17(21), 8110. https://doi.org/10.3390/ijerph17218110 
Weddle, A. (2020). Virtual Workout Trends During Shelter-at-home. Mindbody. Retrieved October 11, 2020, from https://www.mindbodyonline.com/business/education/blog/virtual-workouttrends-during-shelter-home

8 Charts That Explain COVID-19's Impact on the Fitness Industry. (2020, April 5). Fitt Insider.

Retrieved March 23, 2021, from https://insider.fitt.co/covid-19-gym-fitness-app-downloads/ 